\title{
Gender and Socio-Cultural Perspectives through Femicide Case Studies
}

\author{
Kouta C ${ }^{1 *}$, Rousou E ${ }^{1}$, Freysteinsdóttir FJ ${ }^{2}$, Boira \\ $\mathrm{S}^{3}$ and Naudi $\mathrm{M}^{4}$ \\ ${ }^{1}$ Department of Nursing, School of Health Sciences, \\ Cyprus University of Technology, Cyprus \\ ${ }^{2}$ Faculty of Social Work, University of Iceland, Iceland \\ ${ }^{3}$ Department of Psychology and Sociology, University of \\ Zaragoza, Spain \\ ${ }^{4}$ Faculty of Social Well-being University of Malta, Malta \\ *Corresponding author: Christiana Kouta, \\ Department of Nursing, School of Health Sciences, \\ University of Technology, 15 Vragadinou Street, 3041, \\ Limassol, Cyprus
}

Received: March 14, 2017; Accepted: April 03, 2017;

Published: April 10, 2017

\begin{abstract}
Femicide has been defined as the murder of a woman because she is a woman and has devastating consequences for the individual well-being, safety and health of those affected and for the whole society. Socio-cultural and legal issues are highlighted as important factors associated with intimate partner violence and femicide. The purpose of this article is to identify socio-cultural and/ or gender equality issues related to femicide through case studies. It is partly a product of the working group on culture of the COST Action IS1206- Femicide across Europe. Data was collected in a qualitative form from the countries which were involved in the Cost Action working group meetings. The main questions of this article relate to the European countries' socio-cultural issues and the gender equality status of the involved countries related to femicide. Based on the data provided by each country involved, it emerged that patriarchy is still dominant in some European societies. Regulations and laws on gender equality exist in many countries, but it seems that in several cases are not effectively applied. Thus, it is necessary to create the appropriate socio-cultural and gender sensitive environments, supported by effective juridical systems.
\end{abstract}

Keywords: Femicide; Inter-Personal Violence (IPV); Gender; Socio-cultural issues

\section{Introduction}

Violence against women (VAW), the bulk of which consists of intimate partner violence, comprises a wide range of acts - from verbal harassment and other forms of emotional abuse, to physical and/or sexual abuse. Intimate Partner Violence (IPV), including femicide has devastating consequences for the individual well-being, safety and health of those affected and for the whole society, owing to the costs of criminal justice services, increased usage of healthcare facilities and days lost at work [1]. Femicide, the fatal outcome of IPV, not only takes away the life of the victim but also often has a detrimental effect on the victim's children, relatives and innocent bystanders $[2,3]$.

According to Russel [4], femicide is on the extreme end of a continuum of anti-female terror that includes a wide variety of verbal and physical and sexual abuse, such as rape, torture, sexual slavery (particularly in prostitution), incestuous and extra-familial child sexual abuse, physical and emotional battery, sexual harassment, genital mutilation, unnecessary gynecological operations (gratuitous hysterectomies), forced heterosexuality, forced sterilization, forced motherhood, psychosurgery, denial of food to women in some cultures, cosmetic surgery, and other mutilations in the name of beautification. Whenever these forms of terrorism result in death, they become femicides [4]

While the understanding of femicide is limited, evidence shows that a large proportion of femicide cases include women in violent relationships and are committed by a current or former partner [5-7]. More than $35 \%$ of all murders of women globally are reported to be committed by an intimate partner [7].
It is also difficult for researchers to estimate the prevalence of femicide in the world. As WHO highlights, the collection of correct data on femicide is a challenge [7]. The Institutional providers use different criteria and the information is often insufficient. Moreover, in many cases the data collected in many countries only pick up the deaths of women by partner or former partner and omit other 'femicides' related to factors such as family honour or dowry in which crucial socio-cultural issues are involved.

Notwithstanding that the heinous murder of women has been kept hidden for too long [8], violence against women has received increasing international attention as a public health and human rights concern [5,9-10]. Ellsberg et al., propose that the analysis of the phenomenon should incorporate a framework where femicide is understood as a social phenomenon that demands an interdisciplinary approach. In this scenario, the socio-cultural aspects could play a crucial role [9].

Beyond the analysis of the individual and demographic characteristics of victims and perpetrators, femicide has been analyzed from the perspective of different social theories, incorporating different categories of analysis, for a better understanding of the phenomenon [11].

Until recently, a number of acts of violence against women - particularly domestic violence and IPV - were not considered criminal acts [12]. The principal cause of this problem would appear to be the misapplication by the criminal justice system of the concepts of so called 'honour', as well as a more general failure of policing and social welfare authorities to comprehensively understand honourbased violence. 
The Istanbul Convention [13] is the first legally-binding instrument which "creates a comprehensive legal framework and approach to combat violence against women" and is focused on preventing violence against women and domestic violence, protecting victims and prosecuting perpetrators. It characterizes violence against women as a violation of human rights and a form of discrimination against women (Art.3 (a)). Countries should exercise due diligence when preventing violence, protecting victims and prosecuting perpetrators (Art. 5). The Convention also contains a definition of gender in Article 3(c) as "the socially constructed roles, behaviors, activities and attributes that a given society considers appropriate for women and men". Moreover, the treaty establishes a series of offences characterized as violence against women. States which ratify the Convention must criminalize several offences, including: psychological violence (Art.33); stalking (Art.34); physical violence (Art.35); sexual violence, including rape, explicitly covering all engagement in non-consensual acts of a sexual nature with a person (Art.36), forced marriage (Art.37); female genital mutilation (Art.38), forced abortion and forced sterilisation (Art.39). The Convention states that sexual harassment must be subject to "criminal or other legal sanction" (Art. 40). The Convention also includes an article targeting crimes committed in the name of so-called "honour" (Art.42).

Femicide has been addressed in different contexts, including intimate partner violence, stranger violence, rape and other sexual violence, and so called honour and dowry practices, as well as murders associated with gang activity and political violence [14]. According to the Vienna Declaration in 2013, the term "femicide" is understood as: 1) the murder of women as a result of domestic violence/intimate partner violence, 2) the torture and misogynist slaying of women, 3) killing of women and girls in the name of "honour", 4) targeted killing of women and girls in the context of armed conflict, 5) dowry-related killings of women and girls, 6) killing of women and girls because of their sexual orientation and gender identity, 7) the killing of aboriginal and indigenous women and girls because of their gender 8) female infanticide and gender-based sex selection foeticide, 9) genital mutilation related femicide, 10) accusations of witchcraft and 11) other femicides connected with gangs, organized crime, drug dealers, human trafficking, and the proliferation of small arms" [14-15].

According to Devries et al., femicide has been recognized as a human right and a public health issue in urgent need of increased attention [16]. It is considered as a leading cause of premature death for women globally, distinct from homicide and other forms of gender violence [13]. Notwithstanding, femicide is still not adequately researched in Europe. The definitions that have been proposed by researchers and activists, are leading to methodological differences in the collection and interpretation of data [14,17]. While a number of studies have been conducted [18], mainly in highresource areas, reliable and globally comparable data on its nature and prevalence remain scarce [19]. Whilst socio-cultural and legal issues are highlighted as important factors associated with IPV and femicide $[17,20]$, there is an urgent need to contemplate the different faces of femicide and analyze how they manifest in culturally diverse settings [14]. Despite the fact that European countries achieved a high employment rate for women, on average it remains lower than that for men: $69.4 \%$ for men and $58.8 \%$ for women [21].
The purpose of this paper is to explore socio-cultural and/or gender equality issues related to femicide. This is partly a product of the working group on culture of the COST Action IS1206- Femicide across Europe (www.femicide.net). The main research questions were: a) How gender equality status of the involved countries (such as gender pay gap, maternity/paternity leave, male/female data in executive positions and women's status in their countries) relate to femicide or IPV cases? b) Do socio-cultural factors in some European countries' relate to femicide or IPV cases?

\section{Material and Methods}

COST Action IS1206 - "Femicide across Europe" aims to expand knowledge and understanding concerning femicide [22]. The Action has established the first pan-European coalition on Femicide with researchers already studying the phenomenon nationally, in order to advance research clarity, agree on definitions, improve the efficacy of policies for Femicide prevention, and publish guidelines for the use of national policy-makers. Four working groups were created to 1) examine the definition of Femicide, 2) to compare reporting and data collection of Femicide across Europe, 3) to study socio-cultural issues and compare qualitative data on patterns of intimate partner murders and other forms of Femicide and 4) to bring together practitioners and researchers to discuss prevention of Femicide. Data was collected in qualitative form, from the countries $(n=18)$ participating in the two separate working group meetings on culture and femicide, that took place in Malta (2014) and Cyprus (2015) and compared.

The data was provided by the meeting participants in the form of reports, presentations and case studies. The analysis of this data was used to explore the main areas of this study. The first question relates to the gender equality status of the involved countries (such as gender pay gap, maternity/paternity leave, male/female data in executive positions, and women's status in their countries). The second question referred to the European countries' socio-cultural issues related to femicide or IPV cases.

The data presented was related to gender equality and sociocultural issues of each country, such as employment rate and salaries of men and women and the ratio of men and women in high positions. Subsequently case studies related to femicide were presented resulting in the opportunity for the COST Action on Femicide across Europe to critically discuss this phenomenon in relation to national sociocultural factors.

\section{Limitations}

The findings presented in this paper are revealed through qualitative information provided by participating countries of the particular COST Action and are limited to those. Results cannot be generalized.

\section{Results and Discussion}

The main findings, related to femicide, emerged from the analysis of the socio-cultural factors of each country in relation to gender, and gender equality measures. As it is apparent from the data provided by each country involved, regulations and laws on gender equality exist in many countries, such as Austria, Croatia, Cyprus, France, Georgia, Greece, Malta and Poland. Moreover, comparative data shows that in almost all participating countries the leadership positions in politics, 
business and public administration are still largely a male domain. The following supports the above statement: Cyprus has the lowest percentage of women in decision making positions in EU with only $15 \%$; Austria holds a middle-ranking position in regards of the gender gap in labour market participation and women are over-represented as assistant professors but under-represented as professors [23].

Reviewing the collected data of each country, considerable similarities in socio-cultural issues emerged.

\section{Case Studies}

Femicide cases from three of the participating countries were chosen for exploration, one from Malta, one from Iceland and one from Cyprus.

\section{Malta's case study}

On March 2014, Ms SM, 36 years old, married Mr HI, 35 years old. A year later in March 2015, SM was found dead in their apartment by her relatives. Police stated that the victim had five stab wounds in her body. The victim was going through contentious proceedings for marital separation. A few months earlier, her husband had pleaded guilty to charges of harassment after he was accused of having damaged his wife's property and threatened her. He was sentenced to six months in prison, but suspended for two years. He was also warned by the judge not to approach his wife against a 1,000 Euros penalty. At the crime scene a knife was found, which was believed to be the murder weapon. The alleged perpetrator left the country and was arrested under the European and International Arrest Warrants. It is noted that SM had filed three domestic violence reports.

\section{Iceland's case study}

Tara, 35 years old, was stabbed 27 times in her head, face, chest, both arms and both legs by Sebastian, 23 years old. Tara had an 18 year old son. The murder took place at the perpetrator's house, who lived with his father. Both Sebastian and Tara were using amphetamine and other drugs at the time of the incident. Tara had repeatedly phoned the father of her child and told him that Sebastian had taken money from her and she wanted him to help her to get the money back from Sebastian. According to Sebastian, he and Tara had been friends for years. He said that she had been a good friend and they had had a sexual relationship as well, but that they had not been a couple. According to Tara's female relative, who was a witness in the case, Tara and Sebastian had been a couple. According to the same witness, as well as Sebastian's father and the father of Tara's child, there had been prior violent incidents between Tara and Sebastian. Both Tara's relative and the father of her child said that they had seen injuries on Tara as a result of the violence. In addition, the woman claimed that both she and Tara were afraid of Sebastian. According to a psychiatric evaluation, Sebastian had an antisocial personality disorder.

Sebastian had previous charges for physical assault as well as other crimes such as theft, and received a prison sentence of 16 years for the murder of Tara. The presiding judge was a woman and the prosecutor, as well as the defender were males. According to the media, the sentence was not made more severe because of the close relationship, since although Sebastian denied that they had been a couple, he admitted that they had been close friends and had been in a sexual relationship.

\section{Cyprus case study}

Maria, 37 years old, was shot by her 41 year old husband with two shots in head and shoulder. According to witnesses, Maria visited her husband with her two children ( 7 and 13 years old), as they were in the process of separation. Witnesses stated that the couple had an intense argument and the woman got into the car with the two children to leave. The husband shot Maria and his two children with several shots. Then, he committed suicide. The woman and the 7 years old child died, while the other child was seriously injured. It is notable that, two months before Maria filled a complaint for her husband's behavior to the police.

\section{Analysis of the cases based on country reports}

In Malta's culture, historically, the Mediterranean system of "honour and shame" operated as a complex and important system. Reputation and good standing in the community were considered of fundamental importance [24]. Although 'honour' can be considered to have been the pretext for much of the violence perpetrated, particularly within the family, it is not named as such. Honour and shame used to be invoked in cases of 'socially unacceptable' behaviour, primarily of the women and girls in the family, and often involving sexual or romantic relationships. However, the issue of family/male "honour" still exists, unstated, as part of the dominant culture [25].

The Iceland's case reflects a weakness in the legal systems. Although an amendment of the General penal code [Almenn hegningarlög] nr. 19/1940 was approved in 2006, that close relations could increase penalties in cases involving violence; it has rarely been used in the cases involving murders of women, even though they were in intimate relationships with the person who murdered them [26]. Apart from that, the laws on restraining orders have not been sufficiently enforced until recently in a few municipalities. Furthermore, there are examples of sentences that reflect patriarchal views and where witnesses have not been asked thoroughly about prior violence in the relationships of the victims and the perpetrators.

Cyprus case reflects a more 'classical' situation as separation increases violence, particularly where existed. The most common assumptions include masculine possessivenesssexual jealousy and anger are may trigger this-, and the murder is the climax of a history of violence that preceded it. Further, culture and religion play an important role in preserving the patriarchal structure of Cypriot society. Femicide-suicide is more prone to happen when a gun is used [27].

Noteworthy is the fact that in most involved countries the term femicide is not used. It is referred to socially as a "family matter", "family tragedy", "honour kills", "jealousy killing" etc. In most of the cases, women are the victims and men (direct or extended family member/ current or former intimate partner) are the perpetrators. Available statistics in the participating countries generally provide information on incidences of domestic violence and of rape and sexual assault cases reported to the police as opposed to violence against women. The states' emphasis on domestic violence reveals a general lack of awareness and understanding of the scope and nature of violence against women, and worse makes many of these crimes "invisible".

Despite the fact that all countries have a comprehensive legislative 
framework on violence in the family, the legislation is gender neutral and this affects the related departments and services involved in victim support and justice because they also do not mainstream gender in their work. Also a comprehensive legal framework that would cover other forms of violence against women and girls which can take place outside the concept of "family" tends to be lacking. Finally, most EU countries have inadequate victim support systems (e.g. specialized rape crisis centers, specialized shelters and multi-agency victim support services) [1] and this can also be seen to contribute to the high rates of cases that never make it to the courts. Sufficient and dissuasive penalties for the perpetrators are also lacking. It seems that in societies influenced by patriarchy the coercive control and the economic dependence were used as a tool for controlling the woman and preventing her from exiting the violent relationship/marriage.

The majority of the existing related studies regarding crime and gender conclude that gender inequality is one of the structural factors contributing to high rates of female violence victimization, including homicide [28]. However, the findings on the nature of the relationship between gender equality and female violence victimization are inconsistent.

Based on the data provided by each country involved, it is apparent that regulations and laws on gender equality exist in many countries, but it would appear that in many cases they are not actually applied. Moreover, gender pay gap reflects an ongoing discrimination and inequality in the labour market [23]. Gender employment gap is strongly linked to family and care activities, with women more likely to work less hours or being inactive due to family and carerelated activities. The employment rate for women with children is much lower than for women without children in several participating countries, while the opposite is true for men. The employment impact of parenthood on women varies considerably across the participating countries and is extremely high in some cases (Austria 41.5\%) [21]. In Austria, $17 \%$ of the fathers take paternity leave and this can be a turning point for the mother's career. In Croatia the care of children is considered the women's primary responsibility (only $5 \%$ of men use parental leave), in Georgia there is only maternity leave and only half of this leave period is paid. This is very different in Iceland where both mothers and fathers have a right to 3 months paid parental leave each (non-transferable) and three months leave that either of the parents can take: a total of 9 months [23,29]. This might be a good practice for other countries.

Comparison of the data from the presentations of the countries revealed the extent of gender equality varies substantially across participating countries. It can be argued that there is an association between motherhood and disadvantages in the labour market [30].

Another important issue that emerged is that patriarchy still exists and is dominant within some European societies. Traditional and liberal feminist criminologists view patriarchy - a system of society in which men hold the power and women are largely excluded from it - as being responsible for females' violence victimization, including domestic violence, rape, and homicide [28]. The patriarchal basis of the institutions and of the dominant discourse tends to result in a weakness and a lack of trust in the legal system. Some countries (such as Malta, Cyprus, Iceland) have mentioned that society and sociocultural understandings are motivated by patriarchy/ masculinity/ male domination discourses. Consequently, institutions and the civil protection entities operate using patriarchal standards. As has been stated, violence against women is a human rights issue and exists in every society, encompassing different forms of physical, sexual and psychological abuse. However, despite its scale and social impact, it remains largely under-reported and relatively under-researched in key areas [18].

Patriarchal societies seem to increase the likelihood of violations of gender and human rights. Consequently girls and women are discriminated against and treated unequally in many aspects of public or private life. One of the consequences of the above, could be the gender motivated killings and the so called "honour" killings. "Honour" related killings usually include a girl or woman being killed by a male or female family member for an actual or assumed sexual or behavioral transgression, including adultery, sexual intercourse or pregnancy outside marriage - or even for being raped [31]. Often the perpetrators consider this form of femicide a way of protecting the family reputation, of following tradition or of adhering to wrongly interpreted religious demands. Murders in the name of so called 'honour' may also be used to cover up cases of incest, and there are reports of people using the "honour defence" as a way of receiving community and legal acceptance of a non-"honour" murder [14]. Killing of women to "protect the family honour" is among the most tragic consequences and explicit illustrations of embedded, culturally 'accepted' discrimination against women and girls.

Often, femicide is not considered as a criminal offence, but as a problem of the family/relationship. It is important to mention that in some countries there are no data on what are the actual reasons of the murders of women within the family context. Often gender of perpetrator and victim and the relationship between them is still missing in the police data. The lack of systematic data collection and analysis impedes a true understanding of the extent of these crimes and their root causes.

The concept of gender-motivated killings of women and girls is linked to the existence of a system of structural discrimination against them. Stopping gender-motivated killings requires therefore a holistic approach including legal, administrative, policy and other measures to address the social political, economic, socio-cultural and other factors that perpetuate discrimination and violence. Such an approach would also encompass: promoting societal transformation, including the eradication of harmful stereotypes; developing information systems and good quality data on gender-motivated killings; ensuring adequate enforcement by police and the judiciary of civil remedies and criminal sanctions; and ensuring an adequate provision of services for women victims of violence. In terms of analyses the ecological perspective could be useful, incorporating the relationships between the different roles and factors implicated in each of the systems contemplated by the ecological model [32-34]. From an ecological approach, the implementation of public policies, allows for a more integrated analysis that favors the processes of planning and the identification of risk factors (personal, relational, communitarian and sociocultural) that can be incorporated into policies and strategic action programmes [34-35].

\section{Conclusion}

Violence against women and girls is one of the most widespread 
violations of human rights, affecting women and girls of all ages, races and cultures. Today an estimated one in three women will be subject to violence in her lifetime [2]. Femicide - the killing of women because they are women - is the ultimate expression of this form of violence, assuming alarming proportions. Despite the appalling extent of this crime, the global response is not sufficient. Sometimes efforts to fight femicide and violence are not coordinated among relevant stakeholders.

It is necessary to create an appropriate socio-cultural and gender sensitive environment, supported by an effective juridical system [15]. In most of the European countries, there have been many recent positive developments with regard to increasing awareness and commitment towards preventing and combating violence against women, and domestic violence in particular, through a number of programmers. In countries like France, Spain and Portugal there are several national and local observatories against gender violence that are helping to fight violence against women. The collaboration of shelters and other protection centers for victims of violence against women could have a significant effect on the mental and physical care of the victims.

\section{Recommendations of the participating countries include:}

- Acknowledgement of the need for specialized gender-specific services to support the complex range of immediate and longterm needs of women survivors of violence and their children

- Challenge and enhance gender related policies, strategies and laws in regards to gender equality and violence against women as well as policies that support women and families to safely leave violent relationships/environment

- Guarantee of sustainable funding for specialized services, such as women's shelters, help lines and counseling services;

- Systematic and continuous training of professionals on violence against women and to secure funding for it;

- Accessibility of services to women facing multiple discrimination, including migrant, young, older and ethnic minority women;

- Regular monitoring, evaluation and coordination of the public support system for female victims of violence;

- Development of definitions and classifications to be used for surveys, research and administrative statistics, ensuring their consistent use at the national, regional, European and international levels and guaranteeing regular data collection.

- Safeguard the independence and funding of specialized women's NGOs delivering support services for women victims of violence;

\section{Acknowledgments}

Authors thank all working group (WG3) members of the COST Action IS1206- Femicide Across Europe and the Chair of the Action, Dr Shalva Weil, Hebrew University, Israel.

\section{References}

1. Walby S. The cost of domestic violence: Up-date 2009. Executive summary, Lancaster University. 2009.
2. Dobash R, Dobash RE. Who died? The murder of collaterals related to intimate partner conflict. Violence against women. 2012; 18: 662-671.

3. Lewandowski AL, McFarlane J, Campbell CJ, Gary F, Barenski C. He Killed My Mommy! Murder or Attempted Murder of a Child's Mother. Journal of Family Violence. 2004; 19: 211-220.

4. Russell D. The Origin and the Importance of the Term Femicide. 2011.

5. Sagot MF. Strengthening and organization of women and coordinated action between the state and civil society at the local level to prevent and address family violence - research protocol. Gender and Public Health Series Social Response to Family Violence, Women, Health and Development Programme PAHO/WHO. San José: Pan American Health Organization. 2002.

6. Stockl H, Devries K, Rotstein A, Abrahams N, Campbell J, Watts C, et al. The global prevalence of intimate partner homicide: a systematic review. Lancet. 2013; 382: 859-865.

7. WHO. Understanding and addressing violence against women. Femicide. 2012.

8. Weil S. Making femicide visible. Current Sociology. 2015; 1-13.

9. Ellsberg M, Jansen AH, Heise L, Watts C, Garcia-Moreno C. Intimate partner violence and women's physical and mental health in the WHO multi-country study on women's health and domestic violence: an observational study. The Lancet. 2008; 371: 1165-1172.

10. WHO. Global and regional estimates of violence against women: prevalence and health effects of intimate partner violence and non-partner sexual violence. Geneva: World Health Organization. 2013.

11. Corradi C, Marcuello-Servos C, Boira S, Weil S. Theories of femicide and their significance for social research. Current Sociology, 2016: 1-21.

12. European Commission. Feasibility study to assess the possibilities, opportunities and needs to standardise national legislation on violence against women, violence against children and sexual orientation violence. Luxembourg: Publications Office of the European Union. 2010.

13. Council of Europe. Convention on preventing and combating violence against women and domestic violence. Council of Europe Treaty Series - No. 210. 2011.

14. Laurent C, Platzer M, Idomir M. Femicide: A global issue that demands Action. Academic Council on the United Nations System, Vienna: Liaison Office. 2013.

15. Vienna declaration. 2013

16. Devries KM, Mak JY, García-Moreno C, Petzold M, Child JC, Falder G, et al. The global prevalence of intimate partner violence against women. Science. 2013; 340: 1527-1538.

17. Johnson $\mathrm{H}$, Hotton $\mathrm{T}$. Losing control: homicide risk in estranged and intact intimate relationships. Homicide Studies. 2003; 7: 58-84.

18. Eurostat. Gender Statistics. 2015.

19. Rojas S, Maturana C, Maira G. Femicidios en Chile. Santiago de Chile: Naciones Unidas. 2004.

20. Campbell J, Glass N, Sharps P, Laughon K, Bloom T. Intimate partner homicide: review and implications of research and policy. Trauma Violence and Abuse. 2007; 8: 246-269.

21. Eurostat. Employment Statistics. 2014

22. COST Action- Femicide Across Europe website.

23. Government Equality Office. Closing The Gender Pay Gap. 2015

24. O'Reilly M, Sybil. 'Gossip: A Means of Social Control'. In Ronald. Sultana and Godfrey. Baldacchino, (eds) Maltese Society: A Sociological Inquiry (pp. 369-382). Malta: Meriva. 1994.

25. Naudi M. 'Unequal opportunity: The Feminine Predicament'. In J. Inguanez, (ed), Malta Human Development Report (pp. 65-71). Malta: Media Centre Print. 1996. 
26. Iceland's General penal code [Almenn hegningarlög] nr. 19/1940.

27. Ellis D, Stuckless N, Smith C. Marital separation and lethal domestic violence. New York: Routledge 2015.

28. Chon DS. A spurious Relationship of Gender Equality With Female Homicide Victimization: A Cross-National Analysis. Crime \& Delinquency. 2016; 62: 397-419.

29. European Parliamentary Research Service. 2014. "Maternity and Paternity leave in the EU”. 2014

30. European Parliamentary Research Service. Women's Labour Marke Participation in Europe. 2015.
31. Schulze, Erika, Gergoric, Maja. "Maternity, paternity and parental leave: Data related to duration and compensation rates in the European Union". 2015.

32. Bronfenbrenner $U$. Ecology of the family as a context for human development: Research perspective. Developmental Psychology. 1986; 22: 723-742.

33. Edleson J, Tolman R. Ecological interventions for domestic violence. Thousand Oaks, CA: Sage. 1992

34. WHO. World report on violence and health. 2002

35. Heise L. What works to prevent partner violence: An evidence overview. Department for International Development. 2011
J Community Med Health Care - Volume 2 Issue 2 - 2017 Submit your Manuscript | www.austinpublishinggroup.con Kouta et al. (C) All rights are reserved
Citation: Kouta C, Rousou E, Freysteinsdóttir FJ, Boira S and Naudi M. Gender and Socio-Cultural Perspectives through Femicide Case Studies. J Community Med Health Care. 2017; 2(2): 1013. 